\title{
Contribuições da fenomenografia para o ensino e a aprendizagem de competência informacional
}

\author{
Ilídio Lobato Ernesto Manhique \\ Doutorando; Universidade Estadual Paulista, Marília, SP, Brasil; \\ ilidiolobato@gmail.com \\ Helen de Castro Silva Casarin \\ Doutora; Universidade Estadual Paulista, Marília, SP, Brasil; \\ helen.castro@unesp.br
}

\begin{abstract}
Resumo: A complexidade do ambiente digital, derivada do crescimento do volume de dados e da informação, exige um conjunto de habilidades, conhecimentos e atitudes que favoreçam a aprendizagem autônoma dos sujeitos. A competência informacional é parte desses pressupostos que possibilitam o uso crítico e reflexivo da informação. Objetiva-se explorar a abordagem fenomenográfica com o intuito de investigar a aprendizagem a partir da perspectiva dos sujeitos e o seu impacto para o ensino da competência informacional. Com base em uma pesquisa teórica, este estudo fornece subsídios sobre a importância da fenomenografia para a elaboração de propostas com enfoque relacional de competência informacional, que funcionem como alternativa aos padrões e frameworks já existentes, cujas categorias de descrição são definidas a priori. Para tal, analisam-se duas propostas (seven faces of information literacy e six frames for information literacy education) que demonstram como a fenomenografia tem sido usada para examinar a relação entre o indivíduo e a informação. Observa-se que a fenomenografia é uma abordagem de pesquisa com potencialidades para a formulação e reformulação de programas de competência informacional em vários níveis educacionais, em particular no ensino superior. Dada a incipiência desses estudos no contexto brasileiro, sugere-se a realização de novas pesquisas integrando a fenomenografia como forma de aprofundar e diversificar as bases teóricas ligadas à aprendizagem e educação da competência informacional.
\end{abstract}

Palavras-chave: Fenomenografia. Competência informacional. Modelo relacional. Aprendizagem. Ensino.

\section{Introdução}

Nas últimas décadas, a competência informacional tornou-se um dos tópicos dominantes da investigação em Ciência da Informação. O interesse por este objeto deriva das transformações estruturais nos mecanismos de acesso, busca e 
uso da informação, propiciadas pela aplicação intensiva e extensiva das tecnologias de informação e comunicação.

A Ciência da Informação, como campo que se preocupa com os processos de produção, organização, disseminação e uso da informação, assume a vanguarda na formulação de propostas teóricas e práticas para que o uso, a apropriação e, mais recentemente, o compartilhamento da informação sejam eficazes. No âmbito pragmático, esse aspecto constitui a missão e a responsabilidade social da Ciência da Informação (WERSIG; NEVELING, 1975).

Diante desse desafio, o campo desenvolveu vários modelos, quer para a pesquisa escolar (KUHLTHAU, 1991; AMERICAN OF SCHOOL LIBRARIANS, 2007), quer padrões e frameworks de competência informacional para ensino superior (ASSOCIATION OF COLLEGE \& RESEARCH LIBRARY, 2000, 2015; BUNDY, 2004) que servem de parâmetros para fomentar a aprendizagem e a educação da competência informacional.

Desde os finais da década de 1990, o campo de estudos da competência informacional vem registrando alguns incrementos teóricos e metodológicos (ANDRETTA, 2007; MANHIQUE; CASARIN, 2018), que resultam da evolução da área da Ciência da Informação, cada vez mais focada nos aspectos sociais e culturais de produção e uso da informação (HJØRLAND, 2004; CAPURRO, 2007).

Estes desdobramentos têm contribuído para que os programas de competência informacional desloquem o seu tradicional foco instrumental para dar maior ênfase aos processos de aprendizagem e construção do conhecimento através do uso da informação.

Uma das primeiras grandes transformações que ocorreram nos estudos da competência informacional foi apresentada por Luke e Kapitzke (1999), Simmons (2005) e Elmborg (2006), que propuseram a abordagem crítica da competência informacional ou, simplesmente, critical information literacy.

A competência crítica em informação é uma corrente baseada nos princípios da pedagogia crítica de Paulo Freire, propondo uma reflexão acerca do pensamento hegemônico assente nos modelos e standards de competência 
informacional. Os seus defensores (ELMBORG, 2006; TEWELL, 2015) alegam que a padronização de competências e habilidades informacionais impede que os indivíduos desenvolvam a consciência crítica através do questionamento da realidade envolvente.

Por meio de uma pesquisa teórica, o objetivo deste trabalho é analisar a contribuição da fenomenografia para o ensino e a aprendizagem da competência informacional. Do ponto de vista específico, discutem-se os fundamentos teóricos e epistemológicos da fenomenografia, identificam-se alguns modelos relacionais ou fenomenográficos para o ensino e a aprendizagem da competência informacional e a sua contribuição no campo.

Com o intuito de identificar os fundamentos básicos da fenomenografia e da competência informacional, realizou-se a pesquisa bibliográfica, de natureza exploratória. Para a construção do referencial teórico, foram localizados em bases de dados (por meio do Portal de Periódicos da Coordenação de Aperfeiçoamento de Pessoal de Nível Superior - CAPES) artigos que abordassem as seguintes temáticas: competência informacional e fenomenografia. Vários artigos e livros da área da educação foram consultados, considerando que foi nesta área em que a fenomenografia foi utilizada pela primeira vez como abordagem de pesquisa.

\section{Conceitos e epistemologia da fenomenografia}

A fenomenografia é uma abordagem de pesquisa que surgiu na década de 1970, na Suécia, por meio de pesquisas desenvolvidas pelo Departamento de Educação da Universidade de Gotemburgo. Rapidamente, esta perspectiva de pesquisa ultrapassou as fronteiras disciplinares, sendo, atualmente, utilizada em vários campos de conhecimento, tais como Administração, Economia, Física e Ciência da Informação, por exemplo (BRUCE, 1997; BOWDEN, 2000).

Os trabalhos seminais acerca da sua construção teórica, epistemológica e metodológica foram desenvolvidos por autores como Ference Marton, Roger Säljö, Lennart Svensson e Lars-Owe Dahlgren (BOWDEN, 2000).

Do ponto de vista conceitual, a ideia que a fenomenografia procura transmitir está intimamente ligada à sua etimologia. A expressão fenomenografia deriva da palavra grega "phainomenon", que em português 


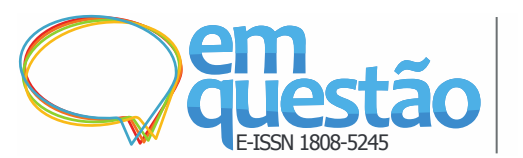

significa "aparência", e "graphein", cujo significado é “descrição". Seguindo a sua etimologia, a fenomenografia pode ser definida como a descrição das coisas como elas nos aparecem (KHAN, 1999).

Marton (1986, p. 31) definiu a fenomenografia como “[...] um método de pesquisa que visa esquematizar as diferentes formas qualitativas pelas quais as pessoas experienciam, conceituam, percebem e compreendem os vários aspectos de um fenômeno e do mundo a sua volta [...]". Partindo desta premissa, a fenomenografia pode ser brevemente, definida como a descrição das concepções que os indivíduos têm acerca de um objeto ou fenômeno à nossa volta.

Este foco, per si, é indicativo das diferenças na natureza do conhecimento produzido pela fenomenografia comparativamente às outras abordagens de pesquisa. Por exemplo, embora a fenomenografia e fenomenologia partilhem alguns aspectos característicos, tais como o fato de ambas serem experienciais, baseadas nos métodos qualitativos e relacionais, existem diferenças fundamentais que as distinguem.

Enquanto a fenomenologia se orienta para a essência do fenômeno, buscando um resultado comum intersubjetivo, isto é, construir uma teoria única sobre a experiência, a fenomenografia centra-se na variação do significado da experiência dos sujeitos sobre um fenômeno. Mais ainda, enquanto a fenomenologia constitui uma abordagem filosófica que se centra na riqueza da experiência individual, a fenomenografia faz parte da tradição empirista que se preocupa em mapear a experiência coletiva dos sujeitos por meio das categorias de descrição (RICHARDSON, 1999).

Por assumir uma visão subjetiva e relativa do conhecimento, a fenomenografia rompe com o ponto de vista objetivista e intersubjetivo que domina as tradicionais pesquisas científicas (SVENSSON, 1997).

Retomando à origem do termo, os pesquisadores da Universidade de Gotemburgo deram início a sua pesquisa com uma inquietação básica sobre a aprendizagem no ensino superior. Para tal formularam as seguintes questões: por que alguns alunos aprendem melhor do que os outros? Por que razão isso acontece? (ANDRETTA, 2007).

Para responder à primeira questão, esses pesquisadores pediram para que os alunos lessem um texto acadêmico indicado e que, posteriormente, em uma 
entrevista individual, cada aluno descrevesse a sua compreensão sobre texto (conteúdo), incluindo as estratégias de aprendizagem adotadas (ato de aprender) (MARTON, 1981, 1986; ANDRETTA, 2007; LIMBERG; SUNDIN; TALJA, 2012).

Analisadas as entrevistas, constatou-se que existia um número limitado de formas qualitativas de compreensão do texto pelos alunos. Essas formas foram sistematizadas em uma estrutura lógica e hierárquica de categorias de descrição que definem, detalhadamente, cada diferente forma de compreender o texto (ANDRETTA, 2007).

Simultaneamente, constatou-se que os alunos empregaram duas estratégias de aprendizagem contrastantes: uma abordagem superficial (surfacelevel processing) e outra profunda (deep-level processing). Os alunos que se preocuparam com a compreensão do conteúdo do texto foram associados à abordagem profunda e, obviamente, aos últimos níveis da estrutura hierárquica das categorias. Os que centraram a sua atenção apenas na tarefa, tentando memorizar o conteúdo do texto, foram associados à abordagem superficial e às categorias mais baixas da experiência (MARTON, 1986; SVENSSON, 1997; ANDRETTA, 2007).

Essas constatações ilustram um dos princípios da fenomenografia, segundo o qual existe uma relação direta entre as formas como as pessoas concebem a aprendizagem e o resultado dessa aprendizagem. Considerando as estratégias (superficial ou profunda) adotadas pelos indivíduos, será suficiente para inferir por que razão algumas pessoas são mais eficazes na aprendizagem do que as outras.

Um dos aspectos que distingue a fenomenografia das demais abordagens de pesquisa é a adoção de uma ontologia não-dualista (Figura 1), em que o indivíduo e o fenômeno não são examinados de forma separada, pois ambos são tidos como parte da mesma experiência (MARTON, 1981; SVENSSON, 1997; BOWDEN, 2000; BRUCE; EDWARDS; LUPTON, 2006; LIMBERG; SUNDIN; TALJA, 2012). 
Figura 1 - Relação não-dualista entre o sujeito e o fenômeno a partir da fenomenografia

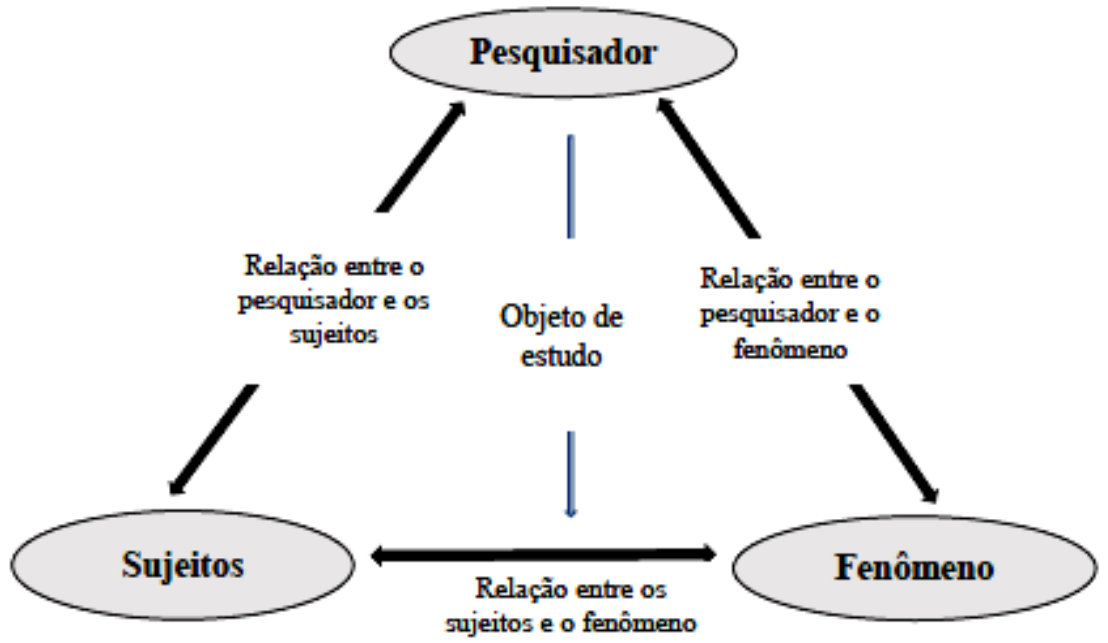

Fonte: Bowden (2005, p. 13, adaptado pelos autores).

Por via disso, a fenomenografia é considerada como uma abordagem relacional de pesquisa, porque o objeto (fenômeno pesquisado) e os sujeitos da pesquisa (as pessoas que vivenciam o fenômeno) não são tratados de forma separada. Pelo contrário, a pesquisa fenomenográfica explora as relações intrínsecas entre os sujeitos e os objetos (MARTON, 1986; SVENSSON, 1997; RICHARDSON, 1999; YATES; PARTRIDGE; BRUCE, 2012).

Esta proposta contrasta como o paradigma positivista, em que as abordagens de pesquisa são, frequentemente, baseadas numa ontologia dualista, segundo a qual a pessoa e o mundo são classificados como entidades distintas (SVENSSON, 1997; YATES; PARTRIDGE; BRUCE, 2012). Essa dicotomia entre o sujeito e objeto é uma das características dos discursos e práticas científicas da Ciência Moderna, em particular no cartesianismo, que se sustenta na separação entre o mundo interior e o exterior.

Pelo fato de assumir as concepções dos sujeitos como seu foco de interesse, a fenomenografia arvora-se nas abordagens de segunda-ordem (second-order perspective), em que o resultado da pesquisa é apresentado em forma de categorias de descrição que refletem as diferentes concepções que as pessoas têm acerca de um fenômeno (MARTON, 1986).

Este é um dos aspectos distintivos da fenomenografia em que, ao contrário da maioria das pesquisas qualitativas - que definem suas categorias e variáveis a priori -, as “categorias de descrição" são descobertas durante a 
pesquisa, e constituem o primeiro e o mais importante resultado deste tipo de investigação (MARTON, 1981, 1986; AKERLIND, 2005).

Sendo a fenomenografia uma abordagem de "segunda ordem", não procura descrever o fenômeno como ele é, o que seria uma abordagem de primeira ordem. Ela descreve os fenômenos como eles são concebidos pelos indivíduos (MARTON, 1981).

Na Ciência da Informação existe uma profusão de pesquisas cujo cerne é a descrição da competência informacional como ela é, isto é, como um elemento de primeira ordem (first-order perspective), como por exemplo, as pesquisas que tem como essência a aplicação de modelos e/ou Standards de competência informacional presentes na literatura da área (BRUCE; EDWARDS; LUPTON, 2006).

Portanto, a fenomenografia constitui uma alternativa viável aos modelos vigentes que apresentam a priori as categorias de competência informacional e que, em alguns casos, pecam por não considerarem a experiência colateral do indivíduo para a aprendizagem e nem o aspecto relacional entre o indivíduo e o fenômeno.

\section{Aportes da fenomenografia à competência informacional}

Os estudos fenomenográficos da competência informacional surgiram como reação à proliferação de modelos instrucionais com características behavioristas e com critérios de avaliação, excessivamente, quantitativos (BRUCE, 1997; LIMBERG; SUNDIN; TALJA, 2012). Alguns desses modelos apresentam etapas sequenciais de aprendizagem da competência informacional (KUHLTHAU, 1991), outros indicam um conjunto de habilidades relativamente prescritivas (ASSOCIATION OF COLLEGE \& RESEARCH LIBRARY ACRL, 2000), que se espera que qualquer aluno do ensino superior desenvolva independentemente do contexto.

Sobre este último aspecto, a ACRL (2015) fez a revisão dos seus Standards publicados no ano 2000 para incluir, dentre outros aspectos, a flexibilidade conceitual e a dimensão sociocultural da aprendizagem da competência informacional. De acordo com esse documento, a competência 
informacional consiste em um conjunto de habilidades, conhecimentos e atitudes que os indivíduos desenvolvem dentro de uma comunidade de práticas.

Quando se fala dos aportes da fenomenografia no domínio da competência informacional, é importante frisar que existem duas grandes contribuições: a primeira, relacionada às categorias relacionais de aprendizagem da competência informacional (BRUCE, 1997, 2003) e, a segunda, ligada aos frameworks para o ensino da competência informacional (BRUCE; EDWARDS; LUPTON, 2006), isto é, frames que servem de subsídios para a integração da competência informacional nos currículos acadêmicos e nos programas instrucionais das bibliotecas.

$\mathrm{Na}$ Ciência da Informação, a perspectiva fenomenográfica teve origem no trabalho de doutorado da pesquisadora australiana Christine Bruce, que pretendia identificar e descrever as concepções de competência informacional dos profissionais do ensino superior, nomeadamente, professores, bibliotecários e administradores.

Essa pesquisa culminou com a construção de um modelo relacional de aprendizagem da competência informacional, designado "Seven faces of information literacy" (BRUCE, 2003; LIMBERG; SUNDIN; TALJA, 2012). Esse modelo (Quadro 1) identifica sete categorias por meio das quais esses profissionais concebem a competência informacional, sendo que as primeiras categorias refletem o entendimento superficial (surface-level processing) e, as últimas, as concepções mais profundas de aprendizagem da competência informacional (deep-level processing).

Quadro 1 - Modelo relacional seven faces of information literacy com sete categorias para compreender a competência informacional de aprendizagem

\begin{tabular}{|l|l|}
\hline \multicolumn{1}{|c|}{$\begin{array}{c}\text { Concepções de competência em } \\
\text { informação }\end{array}$} & \multicolumn{1}{c|}{ Descrição das categorias } \\
\hline Concepção da tecnologia de informação & $\begin{array}{l}\text { Competência informacional éassociada ao uso das tecnologias para } \\
\text { abusca ecomunicação da informação. }\end{array}$ \\
\hline Concepção das fontes de informação & $\begin{array}{l}\text { Acompetência informacional é percebida como o conhecimento das } \\
\text { fontes ea habilidade deacessá-las direta ou indiretamente por meio de } \\
\text { umintermediário. }\end{array}$ \\
\hline Concepção doprocesso & $\begin{array}{l}\text { A competência informacional é descrita como um processo de } \\
\text { execução de um processo informacional, que implica o uso de }\end{array}$ \\
\hline
\end{tabular}




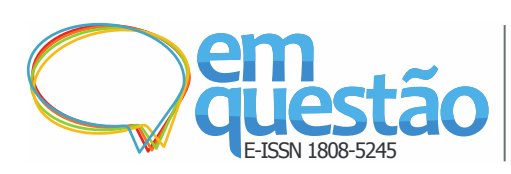

\begin{tabular}{|l|l|}
\hline & $\begin{array}{l}\text { estratégias apropriadas (contextuais) para localizar e usar a } \\
\text { informação. }\end{array}$ \\
\hline Concepção do controle da informação & $\begin{array}{l}\text { A competência informacional é associada ao controle e manipulação } \\
\text { efetiva da informação, através de uso de dispositivos mecânicos. }\end{array}$ \\
\hline $\begin{array}{l}\text { Concepção da construção do } \\
\text { conhecimento }\end{array}$ & $\begin{array}{l}\text { A competência informacional é percebida como construção do } \\
\text { conhecimento, o que difere do armazenamento da informação, } \\
\text { porque envolvea aplicaçãoda análise crítica da leitura da informação. }\end{array}$ \\
\hline Concepção da extensãodo conhecimento & $\begin{array}{l}\text { A competência informacional é associada à aplicação do } \\
\text { conhecimento e adoção de perspectivas pessoais de tal forma que se } \\
\text { obtémnovas intuiçães. }\end{array}$ \\
\hline Concepção do saber & $\begin{array}{l}\text { Acompetência informacional éassociada aouso inteligentee ético da } \\
\text { informação, considerando os aspectos históricos eculturais. }\end{array}$ \\
\hline
\end{tabular}

Fonte: Adaptado de Bruce (2003).
Contribuições da fenomenografia para o ensino e a aprendizagem de competência informacional Ilídio Lobato Ernesto Manhique e Helen de Castro Silva Casarin

Embora este modelo tenha sido produzido há mais de 20 anos, os seus fundamentos continuam impactantes em vários estudos empíricos da Ciência da Informação. Lupton (2004) explorou a abordagem relacional da competência informacional, examinando as relações dos estudantes com a informação em um contexto de resolução de problemas no ensino superior. O seu estudo gerou três categorias que descrevem o grau de engajamento dos alunos com as práticas informacionais. Tais categorias são:

- Busca de evidências: uma abordagem instrumental, em que o foco está centrado na tarefa e não nos aspectos transferíveis e transformacionais do processo de aprendizagem;

- Desenvolvimento de um argumento: internalização da informação e definição de parâmetros para a construção do conhecimento;

- Aprendizagem como responsabilidade social: que oferece uma visão compreensiva da competência informacional como uma inter-relação entre a tarefa, a informação e a aprendizagem. A competência informacional é vista como um agente transformacional que opera em ambos os contextos: pessoal e social.

Manhique e Casarin (2018) fizeram um levantamento na SCOPUS, na Web of Science e na Library and Information Science Abstracts (LISA ProQuest), tendo constatado que grande parte das pesquisas que adota a fenomenografia como abordagem de investigação utiliza esse mesmo modelo (BRUCE, 2003) como seu ponto de partida. No caso do Brasil, o levantamento 
foi feito na Base de Dados Referenciais de artigos de Periódicos em Ciência da Informação (BRAPCI) e na Biblioteca Digital Brasileira de Teses de Dissertações (BDTD), onde não foi encontrado nenhum registro de publicação que aborde a competência informacional nesta perspectiva.

Considerando os aspectos experienciais da fenomenografia, Bruce (2013) propôs uma reconceitualização da competência informacional. Segundo Bruce, Edwards e Lupton (2006, p. 4),

[...] competência informacional não é um conjunto de habilidades, competências e características. É um complexo de diferentes modos de interagir com a informação, o qual inclui: conhecimento sobre o mundo da informação (frame de conteúdo), um conjunto de competências ou habilidades (frame de competência), um modo de aprendizagem (frame de aprendizagem), práticas sociais, contextuais e situadas (frame de relevância pessoal) e as relações de poder na sociedade e responsabilidade social (frame de impacto social).

Segundo Bruce et al. (2017), a abordagem da fenomenografia aplicada a competência informacional passou a ser conhecida como informed learning, a qual se concentra na experiência das pessoas e no uso criativo e reflexivo da informação com o objetivo de aprender. Estes autores consideram a informed learning como uma evolução qualitativa do modelo seven faces of information literacy, posicionando a competência informacional como uma forma de aprendizagem, ou seja, uma prática que estabelece uma interdependência entre o uso da informação e a aprendizagem.

Figura 2 - Modelo de informed learning que reflete a abordagem relacional

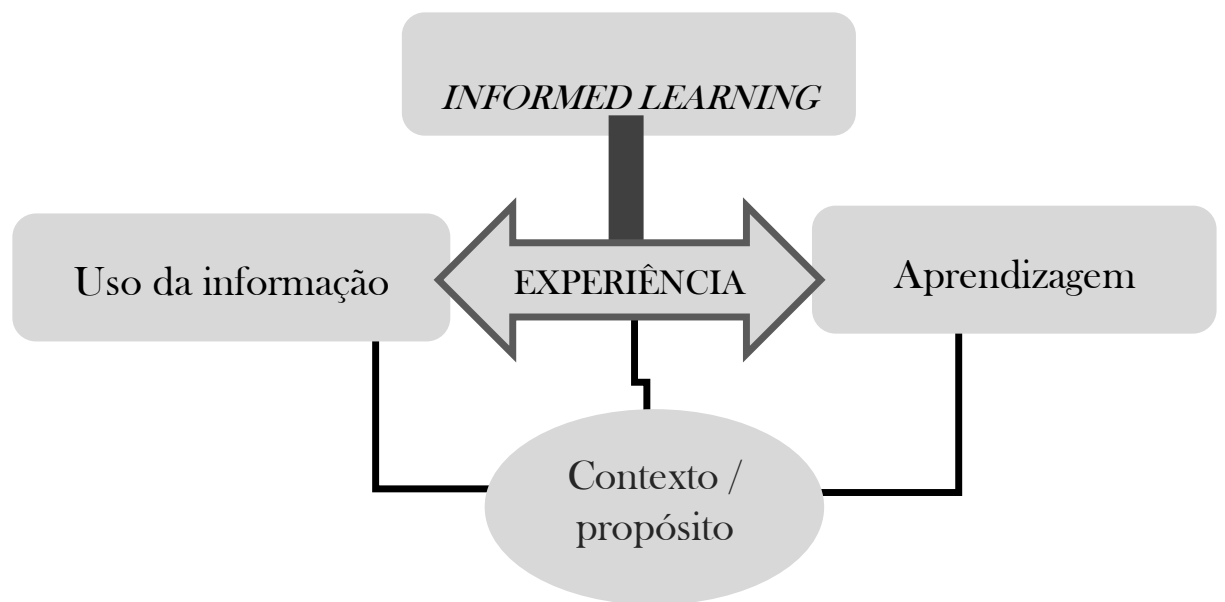

Fonte: Elaborado pelos autores. 
Os trabalhos de Christine Bruce tiveram influência na revisão do Australian and New Zealand information literacy framework: principles, standards and practice, um documento que orienta a aprendizagem da competência informacional no ensino superior, elaborado por Alan Bundy. Na sua segunda edição, Bundy (2004) incorporou a ideia de que a competência informacional não fosse tratada como um simples conjunto de habilidades genéricas aplicáveis em quaisquer situações. Considerou a necessidade de que os frameworks incluíssem a dimensão relacional, isto é, que a competência informacional fosse, também, entendida como parte da relação experiencial que os indivíduos estabelecem com a informação em circunstâncias específicas.

\subsection{Modelo relacional de ensino da competência informacional}

Conforme anteriormente evidenciado, os princípios da abordagem fenomenográfica impactam no ensino e na aprendizagem da competência informacional. Na seção anterior foram identificadas algumas contribuições da fenomenografia à aprendizagem da competência informacional, tendo como ponto de partida o trabalho seminal apresentado na Ciência da Informação por Christine Bruce.

Nesta subseção discute-se de que forma a abordagem relacional ou fenomenográfica contribui para o ensino da competência informacional, identificando subsídios para os programas instrucionais das bibliotecas, bem como para a sua integração nos currículos acadêmicos. Para tal, elegeu-se o modelo relacional de ensino da competência informacional, designado Six frames for information literacy education, concebido por Bruce, Edwards e Lupton (2006), e que tem tido repercussão na educação da competência informacional no contexto dos países anglo-saxônicos.

Estes frames foram desenvolvidos como uma ferramenta conceitual para ajudar a todos os envolvidos no ensino da competência informacional a analisar e a refletir sobre a variedade de influências teóricas implícitas ou explícitas que interferem na abordagem deste objeto (BRUCE; EDWARDS; LUPTON, 2006).

O Quadro 2 identifica e descreve as características de cada um dos frames, destacando a sua orientação prática, seu foco, os critérios de avaliação dos resultados de aprendizagem e um exemplo prático para cada frame. 
Quadro 2 - Caracterização das categorias de ensino da competência informacional no ensino superior

\begin{tabular}{|c|c|c|c|c|}
\hline Frames & Orientação & Foco & Avaliação & $\begin{array}{l}\text { Exemplos para a } \\
\text { aprendivageme } \\
\text { ensino da } \\
\text { competência } \\
\text { informacional } \\
\end{array}$ \\
\hline $\begin{array}{l}\text { Frame do } \\
\text { conteúdo }\end{array}$ & $\begin{array}{l}\text { Neste frame os } \\
\text { usuários adotam } \\
\text { uma orientação } \\
\text { disciplinar. }\end{array}$ & $\begin{array}{l}\text { Eles enfatizam(foco) o } \\
\text { que os indivíduos } \\
\text { deveriam aprender } \\
\text { sobre a competência } \\
\text { informacional. }\end{array}$ & $\begin{array}{l}\text { A avaliação da } \\
\text { competência } \\
\text { informacional } \\
\text { tipicamente } \\
\text { quantifica o quanto } \\
\text { foi aprendido. }\end{array}$ & $\begin{array}{l}\text { Ensino em módulo } \\
\text { específico dentro de } \\
\text { uma disciplina, através } \\
\text { de palestras sobre um } \\
\text { conjunto de } \\
\text { ferramentas e técnicas } \\
\text { deinformação. }\end{array}$ \\
\hline $\begin{array}{l}\text { Frame da } \\
\text { competênc } \\
\text { ia }\end{array}$ & $\begin{array}{l}\text { Os usuários deste } \\
\text { frame tendem a } \\
\text { adotar uma } \\
\text { orientação } \\
\text { comportamental } \\
\text { ou de } \\
\text { desempenho. }\end{array}$ & $\begin{array}{l}\text { Perguntam o que os } \\
\text { alunos seriam capazes } \\
\text { de fazer e qual é o seu } \\
\text { nível de competência. } \\
\text { Geralmente segue-se } \\
\text { um programa de } \\
\text { instrução para } \\
\text { aquisição das } \\
\text { competências exigidas. }\end{array}$ & $\begin{array}{l}\text { A avaliação da } \\
\text { competência } \\
\text { informacional } \\
\text { procura, tipicamente, } \\
\text { que nível de } \\
\text { habilidades foi } \\
\text { alcançado. }\end{array}$ & $\begin{array}{l}\text { Desenho de uma } \\
\text { instrução sequenciada } \\
\text { para ensinar o uso de } \\
\text { um recurso eletrônico, } \\
\text { complementado por } \\
\text { um teste para } \\
\text { determinar o nível de } \\
\text { habilidades alcançado } \\
\text { peloindivíduo. }\end{array}$ \\
\hline $\begin{array}{l}\text { Frame do } \\
\text { aprender a } \\
\text { aprender }\end{array}$ & $\begin{array}{l}\text { Os profissionais } \\
\text { que usam este } \\
\text { frame, } \\
\text { geralmente, } \\
\text { adotam uma } \\
\text { orientação } \\
\text { construtivista. }\end{array}$ & $\begin{array}{l}\text { Pergunta-se o que } \\
\text { significa pensar como } \\
\text { um profissional } \\
\text { competente em } \\
\text { informação. Eles estão, } \\
\text { também, interessados } \\
\text { no que pode ajudar os } \\
\text { indivíduos a construiro } \\
\text { conhecimento de } \\
\text { forma apropriada, e a } \\
\text { desenvolver processos } \\
\text { de aprendizagem que } \\
\text { fomentem padrões de } \\
\text { pensamento } \\
\text { profissional. }\end{array}$ & $\begin{array}{l}\text { A avaliação da } \\
\text { competência } \\
\text { informacional } \\
\text { procura determinar } \\
\text { se os processos de } \\
\text { uso de informação } \\
\text { são baseados em } \\
\text { uma aprendizagem } \\
\text { consciente ou como } \\
\text { as pessoas abordam } \\
\text { uma determinada } \\
\text { questão. }\end{array}$ & $\begin{array}{l}\text { Definição de um } \\
\text { problema da vida real } \\
\text { em que a necessidade } \\
\text { de acessar, avaliar e } \\
\text { usar informações de } \\
\text { uma variedade de } \\
\text { fontes é essencial e, } \\
\text { adequadamente, } \\
\text { fundamentada. }\end{array}$ \\
\hline $\begin{array}{l}\text { Frame de } \\
\text { relevância } \\
\text { pessoal }\end{array}$ & $\begin{array}{l}\text { Os que usam } \\
\text { este frame } \\
\text { adotam uma } \\
\text { orientação } \\
\text { experiencial }\end{array}$ & $\begin{array}{l}\text { Emrelaçãoà educação } \\
\text { da competência } \\
\text { informacional, eles } \\
\text { precisam que as } \\
\text { pessoas desenvolvam } \\
\text { o senso sobre o que a } \\
\text { competência } \\
\text { informacional pode } \\
\text { fazer por eles. Eles se } \\
\text { interessam pelos tipos } \\
\text { de experiências } \\
\text { necessárias para } \\
\text { permitir que os alunos } \\
\text { se envolvam com um }\end{array}$ & $\begin{array}{l}\text { A avaliação é } \\
\text { tipicamente baseada } \\
\text { em portfólios e na } \\
\text { autoavaliação dos } \\
\text { alunos. }\end{array}$ & 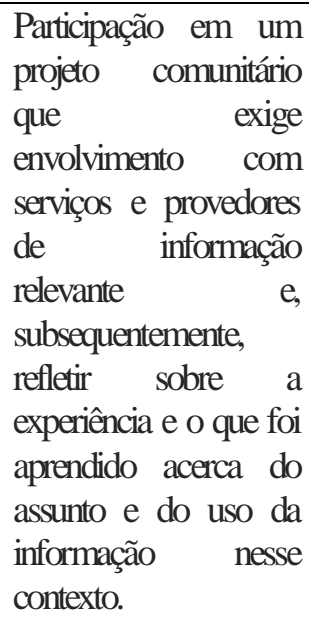 \\
\hline
\end{tabular}




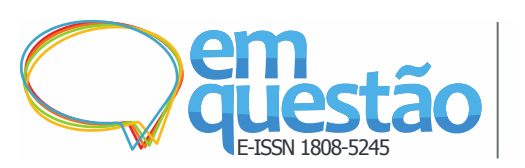

Contribuições da fenomenografia para o ensino e a aprendizagem de competência informacional

Ilídio Lobato Ernesto Manhique e Helen de Castro Silva Casarin

\begin{tabular}{|c|c|c|c|c|}
\hline & & assunto particular. & & \\
\hline $\begin{array}{l}\text { Frame do } \\
\text { impacto } \\
\text { social }\end{array}$ & $\begin{array}{l}\text { Os que utilizam } \\
\text { este frame } \\
\text { geralmente } \\
\text { adotam uma } \\
\text { orientação de } \\
\text { reforma social. }\end{array}$ & $\begin{array}{l}\text { O seu interesse } \\
\text { concentra-se em como } \\
\text { a competência } \\
\text { informacional impacta } \\
\text { a sociedade e em } \\
\text { como ela pode ajudar } \\
\text { as comunidades a } \\
\text { resolver os seus } \\
\text { problemas } \\
\text { significativos. }\end{array}$ & $\begin{array}{l}\text { Os alunos poderiam } \\
\text { ser avaliados em } \\
\text { termos da sua } \\
\text { compreensão sobre } \\
\text { como a competência } \\
\text { informacional } \\
\text { poderia influenciar os } \\
\text { problemas sociais. }\end{array}$ & $\begin{array}{l}\text { Centrar a atenção dos } \\
\text { alunos sobre várias } \\
\text { questões e valores } \\
\text { ligados à exclusão } \\
\text { digital, propondo } \\
\text { tarefas relacionadas às } \\
\text { políticas, tecnologia e } \\
\text { treinamento desenhado } \\
\text { para ajudar a superar } \\
\text { essa exclusão. }\end{array}$ \\
\hline $\begin{array}{l}\text { Frame } \\
\text { relacional }\end{array}$ & $\begin{array}{l}\text { Os que utilizam } \\
\text { este frame se } \\
\text { orientam para as } \\
\text { formas pelas } \\
\text { quais os alunos } \\
\text { estão cientes da } \\
\text { competência } \\
\text { informacional ou } \\
\text { de umfenômeno } \\
\text { específico } \\
\text { associado à } \\
\text { competência } \\
\text { informacional. }\end{array}$ & $\begin{array}{l}\text { Eles se interessam em } \\
\text { projetar experiências } \\
\text { que ajudam os alunos } \\
\text { a discernir formas mais } \\
\text { poderosas de conceber } \\
\text { o fenômeno em } \\
\text { questão. }\end{array}$ & 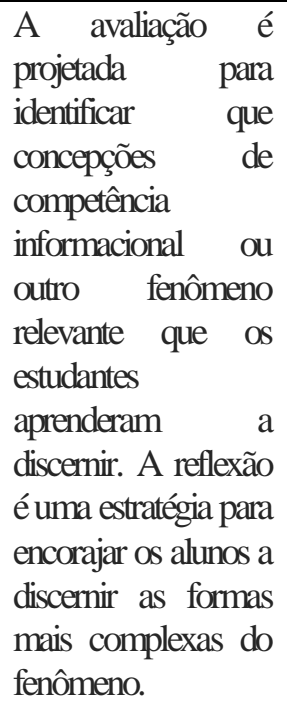 & $\begin{array}{l}\text { Ajudar os estudantes a } \\
\text { aprender a fazer buscas } \\
\text { na internet, projetando } \\
\text { experiências que } \\
\text { focalizem a sua atenção } \\
\text { em aspectos } \\
\text { previamente não } \\
\text { discernidos do } \\
\text { fenômenoemcausa. }\end{array}$ \\
\hline
\end{tabular}

Fonte: Adaptado (BRUCE; EDWARDS; LUPTON, 2006).

Importa frisar que os primeiros cinco frames não são necessariamente recentes, pois estão presentes em vários documentos e pesquisas que tratam sobre a integração e ensino da competência informacional na educação superior (ANDRETTA, 2007).

As autoras dos Six frames associam as primeiras duas categorias à influência de entidades externas, em que a informação é transmitida de uma pessoa para outra (frame do conteúdo e o frame da competência). Nessas categorias, a informação assume uma perspectiva objetiva (ANDRETTA, 2007; BRUCE; EDWARDS; LUPTON, 2006). Do terceiro ao quinto frame, a informação assume uma condição subjetiva (fatores internos), porque é aberta a múltiplas interpretações e reflexões, levando a sua internalização pelo indivíduo (BRUCE; EDWARDS; LUPTON, 2006).

Contudo, no frame relacional ou fenomenográfico, o qual será mais detalhado aqui, a informação assume uma perspectiva não-dualista, isto é, ela é, simultaneamente, objetiva e subjetiva (BRUCE; EDWARDS; LUPTON, 2006) 
e "[...] as mudanças da primeira para a última fazem parte do processo de transformação cognitiva do indivíduo [...]”" (ANDRETTA, 2007, p. 161, tradução nossa).

Os usuários deste frame se interessam, simultaneamente, com o conteúdo (o fenômeno em si) e em como esse fenômeno é concebido ou experienciado (BRUCE; EDWARDS; LUPTON, 2006). Isto tem suporte nos princípios fenomenográficos em que a experiência é descrita em torno de duas dimensões: o quê (conteúdo da experiência) e o como (o ato de aprender).

Neste frame busca-se estimular os indivíduos a discernir os fenômenos nas suas formas mais complexas. Conforme foi exposto nas seções anteriores, a fenomenografia é uma abordagem de pesquisa que visa mapear as diferentes concepções que os indivíduos têm acerca de um fenômeno. Essa visão de aprendizagem foi classificada como teoria de variação (SVENSSON, 1997; MARTON; PONG, 2005).

Svensson (1997) reporta que existe uma relação intrínseca entre as formas como os professores concebem o ensino e a aprendizagem e a maneira como abordam o ato de ensinar. A partir disto, pode se inferir que a nossa forma de ver a competência informacional e as nossas concepções de ensino e aprendizagem podem influenciar a nossa abordagem em relação à educação da competência informacional.

No contexto brasileiro, a integração dessa abordagem de pesquisa no domínio da competência informacional continua incipiente (MANHIQUE; CASARIN, 2018). Em uma pesquisa bibliográfica e cientométrica realizada por Manhique e Casarin (2018), constatou-se que os estudos da competência informacional com foco fenomenográfico continuam concentrados no contexto anglo-saxônico, com destaque para a Austrália e o Reino Unido, que são os países que reúnem a maioria dos pesquisadores que se dedica a este domínio de estudos na Ciência da Informação.

Em um contexto em que vários organismos internacionais se preocupam em integrar os aspectos contextuais e experienciais na promoção da competência informacional, a fenomenografia apresenta esse potencial para o fortalecimento da competência informacional como uma forma de aprendizagem baseada na experiência. 
Portanto, a inclusão da experiência nos estudos da competência informacional é de importância extrema para a intervenção educacional (FORSTER, 2013), visto que conhecendo a superficialidade e/ou profundidade com que os usuários abordam este fenômeno, pode se contribuir para a reformulação dos programas instrucionais desenvolvidos pelas bibliotecas.

Similarmente, se conhecidas as categorias da experiência dos indivíduos acerca de desse objeto, poder-se-á reformular as formas de sua integração nos projetos pedagógicos e nos currículos acadêmicos. Ou seja, a fenomenografia tem o potencial de ajudar na reformulação das formas como se ensina e/ou se aprende a competência informacional nos diversos programas educacionais, sejam eles formais ou informais.

\section{Considerações finais}

A partir da análise dos fundamentos da fenomenografia e da competência informacional, observamos que esta perspectiva de pesquisa continua incipiente no campo da Ciência da Informação, sobretudo no contexto brasileiro. Essa abordagem, que surgiu como reação ao positivismo na pesquisa educacional, não deve ser entendida como ruptura com as formas tradicionais de prática e de pesquisa da competência informacional, mas como alternativa para que se compreenda a amplitude das dimensões teóricas e epistemológicas que compõe este domínio de investigação.

Sendo a competência informacional um objeto teoricamente multifacetado, os seus conceitos (plural) serão, sempre, determinados pelas lentes teóricas empregadas pelos pesquisadores. Se o foco se centrar nas tecnologias, a sua prática terá uma ênfase instrumental, mas se a ideia é fomentar um conjunto de aprendizagens através do uso da informação, a competência informacional irá enfatizar as dimensões cognitivas, éticas e sociais que interferem na produção, busca e uso da informação.

$\mathrm{O}$ enfoque fenomenográfico da competência informacional traz em evidência a necessidade de uma abordagem relacional, em que fenômeno e os sujeitos são tidos como entes da mesma situação. Assim sendo, a competência informacional deve ser analisada a partir da experiência dos indivíduos, cujas 
concepções são estruturadas em categorias de descrição que refletem o número de formas qualitativamente diferentes de se compreender esse fenômeno.

Essa compreensão pode gerar dois níveis de aprendizagem: uma superficial, que se relaciona às primeiras categorias, e outra profunda, que reporta às últimas categorias. Esse processo é fundamental para a intervenção educacional, pois o conhecimento dessas categorias por parte dos professores, bibliotecários e de outros agentes educacionais pode contribuir para a reformulação das formas como se ensina e/ou se aprende a competência informacional nos diversos programas educacionais.

As propostas das seven faces of information literacy e dos six frames for information literacy education servem de evidência para mostrar como a fenomenografia vem repercutindo no delineamento das políticas e programas de competência informacional em vários países, com particular incidência no contexto anglo-saxônico.

Dada a incipiência de pesquisas no contexto brasileiro e em outros países de língua portuguesa, esta abordagem de pesquisa abre um campo fértil de estudos para o alargamento das perspectivas teóricas, epistemológicas e metodológicas da competência informacional na Ciência da Informação desses países.

\section{Referências}

ÅKERLIND, Gerlese. Learning about phenomenography: Interviewing, data analysis and the qualitative research paradigm. In: BOWDEN, John; GREEN, Pam (orgs.). Doing developmental phenomenography. Melbourne: RMIT University Press, p. 62-73, 2005.

AMERICAN ASSOCIATION OF SCHOOL LIBRARIANS. Standards for the 21st - century learner. America Library Association, Chicago, 2007.

ANDRETTA, Suse. Phenomenography: a conceptual framework for information literacy education. Aslib Proceedings, [s.1.], v. 59, n. 2, p. 152-168, 2007.

ASSOCIATION OF COLLEGE \& RESEARCH LIBRARIES. Information Literacy Competency Standards for Higher Education. America Library Association, 2000. 
ASSOCIATION OF COLLEGE \& RESEARCH ASSOCIATION. Framework for Information Literacy for Higher Education. American Library

Association, February 9, 2015.

BOWDEN, John. The nature of phenomenographic research. In: BOWDEN, John A.; WALSH, Eleonor (eds.). Phenomenography. Melbourne: RMIT University Press, 2000.

BOWDEN, John. Reflections on the phenomenographic team research process. In: BOWDEN, John; GREEN, Pam (eds.). Doing developmental phenomenography. Melbourne: RMIT University Press, 2005.

BRUCE, Christine Susan. Information literacy research and practice: An experiential perspective. In: KURBANOĞLU, Serap et al. (eds). Worldwide Commonalities and Challenges in Information Literacy Research and Practice. [s.1.]: Springer, p. 11-30, 2013.

BRUCE, Christine Susan. Seven faces of information literacy. Adelaide: Auslib Press, 1997.

BRUCE, Christine Susan. Las siete caras de la alfabetización en información en la enseñanza superior. Anales de Documentación, Murcia, n. 6, p. 289-294, 2003.

BRUCE, Christine Susan; EDWARDS, Sylvia Lauretta; LUPTON, Mandy. Six Frames for Information Literacy Education: A conceptual framework for interpreting the relationships between theory and practice. Innovations in Teaching and Learning Information and Computer Science, [s.1.], v.5, n.1, 2006.

BRUCE, Christine Susan et al. Information literacy and informed learning: conceptual innovations for IL research and practice futures. Journal of Information Literacy, [s.1], v. 11, n. 1, p. 4-22, 2017.

BUNDY, Alan. Australian and New Zealand Information Literacy Framework principles, standards and practice. 2. ed. Adelaide: Australian and New Zealand Institute for Information Literacy, 2004.

CAPURRO, Rafael. Epistemología y ciencia de la información. Enlace: Revista Venezolana de Información, tecnología y conocimiento, Maracaibo, v. 4, n. 1, p. 11-29, 2007.

ELMBORG, James. Critical Information Literacy: Implications for Instructional Practice. The Journal of Academic Librarianship, [s.1], v.32, n.2, p.192-199, 2006.

FORSTER, Marc. Data-analysis issues in a phenomenographic investigation of information literacy in nursing. Nurse Researcher, [s.1], v. 21, n. 2, p. 30-34, 2013. 


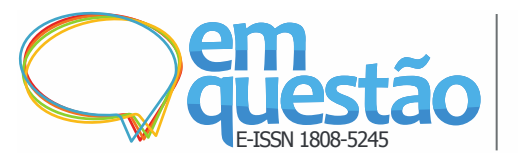

Contribuições da fenomenografia para o ensino e a aprendizagem de competência informacional Ilídio Lobato Ernesto Manhique e Helen de Castro Silva Casarin

HJØRLAND, Birger. Domain Analysis: A Socio-Cognitive Orientation for Information Science Research. Bulletin of the American Society for Information Science and Technology, [s.1], 2004.

KUHLTHAU, Carol Collier. Inside the search process: information seeking from the user's perspective. Journal of the American Society for Information Science, [s.1.], v. 42, n. 5, p. 361-371, 1991.

LIMBERG, Louise; SUNDIN, Olof; TALJA, Sanna. Three theoretical perspectives on information literacy. Human It, Borås, v. 11, n. 2, p. 93-130, 2012.

LUKE, Allan; KAPITZKE, Cushla. Literacies and libraries - Archives and cybraries. Pedagogy, Culture and Society, [s.1.], v. 7, n. 3, p. 467-491, 1999.

LUPTON, Mandy. The Learning Connection. Information Literacy and the Student Experience. Adelaide: Auslib Press, 2004.

MANHIQUE, Ilídio Lobato Ernesto; CASARIN, Helen de Castro Silva. Estrutura intelectual dos estudos da competência informacional na perspectiva fenomenográfica: uma análise por meio da citação e cocitação. Revista Iberoamericana de Ciência da Informação, Brasília, v. 11, n. 3, p. 751-768, 2018.

MARTON, Ference. Phenomenography - describing conception world around us. Instructional Science, [s.1.], v. 10, p. 177-200, 1981.

MARTON, Ference. Phenomenography: a research approach to investigating different understandings of reality. Journal of Thought, [s.1.], v. 21, n. 3, p. 2849, 1986.

MARTON, Ference; PONG, Wing Yan. On the unit of description in phenomenography. Higher Education Research \& Development, [s.1.], v. 24, n. 4, p. 335-348, 2005.

RICHARDSON, John. The Concepts and methods of phenomenographic research. Review of Educational Research, [s.1.], v. 69, p. 53-82, 1999.

SIMMONS, Michelle. Librarians as Disciplinary Discourse Mediators: Using genre theory to move toward critical information literacy. Libraries and the Academy, [s.1.], v. 14, n. 2, p. 297-311, 2005.

SVENSSON, Lennart. Theoretical foundations of phenomenography. Higher Education Research \& Development, [s.1.], v. 16, n. 2, p. 159-171, 1997.

TEWELL, Eamon. A decade of critical information literacy: a review of the literature. Communications in Information Literacy, [s.1.], v. 9, n. 1, p. 24-43, 2015. 
WERSIG, Gernot; NEVELING, Ulrich. The phenomena of interest to Information Science. Information Scientist, [s.1.], v. 9, n. 4, p. 127-140, 1975.

YATES, Christine; PARTRIDGE, Helen; BRUCE, Christine Susan. Exploring information experiences through phenomenography. Library and Information Research, [s.1.], v. 36, n. 112, p. 96-112, 2012.

\title{
Contributions of the phenomenographic approach for information literacy learning and education
}

\begin{abstract}
The complexity of digital environment derived from the growing volume of data and information requires a set of skills, atitudes and knowledge that favor people autonomous learning. The information literacy is part these assumptions that allow critical and reflexive use of information. This research explores the phenomenographic approach to investigate the learner-based learning and its impact on information literacy education. Based on literature review, this research provides insights about the importance of phenomenography to conceive relational models of information literacy, which can be an alternative to the prevailing standards and frameworks which categories of description are defined priori. In this work were analyzed two relational models of information literacy, namely, "seven faces of information literacy" and "six frames for information literacy education", to demonstrate how phenomenography has been used to examine the relation between individuals and information. It concludes that phenomenograpy is an approach with unlimited potentialities to help to design and redesign information literacy programs in several educational levels. Given the incipiency of this kind of studies in Brazilian context, we suggest that new studies about information literacy using phenomenographic perspective are necessary in order to deepen the theoretical and methodological bases of information literacy learning and education.
\end{abstract}

Keywords: Phenomenography. Information literacy. Relational model. Learning. Education.

Recebido: 27/01/2019

Aceito: 10/05/2019 